\title{
An Empirical Study of the Importance and Uniqueness of Stakeholder Management in China
}

\author{
Luo Jing, Yin Jian \\ ${ }^{1}$ Department of Business and Management, Huizhou University, Huizhou, China \\ ${ }^{2}$ Huiyun Titanim Co. Limited, Yunfu, China \\ Email: luojing@hzu.edu.cn, hyinjian@gmail.com
}

Received 30 June 2014; revised 18 August 2014; accepted 21 August 2014

Copyright @ 2014 by authors and Scientific Research Publishing Inc.

This work is licensed under the Creative Commons Attribution International License (CC BY). http://creativecommons.org/licenses/by/4.0/

c) (i) Open Access

\begin{abstract}
Chinese economic reform in the early 1980s had introduced China modern project management theories and techniques, which had been widely observed in various industries and business sectors ever since. However, empirical studies of project stakeholder practice presented before indicate that Chinese people have learned the definition of modern projects but they give a new definition to project success according to their own working environment [1], and that stakeholder management is one of the areas where major differences between Chinese and Western projects exist. Therefore, understanding the uniqueness of stakeholder relationship in Chinese projects is one of the key factors for project success. This paper a) explores informal relationship among key stakeholders in Chinese projects and b) examines the influences their relationships have on project success in China. The final findings of this paper aim to provide best practice for understanding and managing key stakeholders in Chinese projects.
\end{abstract}

\section{Keywords}

Project Management, Stakeholder Management, Stakeholder Relationships, Chinese Projects, Project Success, Guanxi

\section{Introduction}

In project management, there are basically two kinds of relationships among stakeholders: formal one and informal one. Formal relationship refers to official relationship formed within work places and is often hierarchical, while informal relationship means personal relationship developed outside work places and is often among 
people on the same hierarchy level [2]. Among research literatures which study Chinese project stakeholder management, there is one widely accepted definition of guanxi: "a trust-commitment/power-dependence relationship among firm stakeholders that is dynamic (cumulative, utilitarian, and long-term), yields socioeconomic benefits (positive work morale, group harmony, and enhanced effectiveness), and is substantively distinct from bribery" [3]. In this study, we firstly analyze the relationship between guanxi and project success in China, then present guanxi within project-based organizations and with clients.

\section{Literature Review}

Chinese cultural roots and rules from a legacy of Confucianism, whose doctrine is avoiding conflict and finding balance between everything, encourage a more collectivistic mindset [4]. The impact of Confucianism on Chinese people's way of thinking is greater than any other traditional philosophies in history. After 2500 years, Chinese business persons are still under this influence as they all consider guanxi as a deeply rooted cultural norm. One example is that, in China, two key factors of business/project success, trust and commitment are predicated on friendship that is developed through guanxi rather than contracts [5].

Within Chinese organizations, informal relationship (guanxi) is effective in creating group harmony, which not only leads to a higher level of mutual understanding and trust but also helps to solve resource competition problems between different projects within an organization [6]. Among a wealth of studies of project stakeholder management, both Western and Chinese researchers found that guanxi has a heavy influence on Chinese project management practice [7]. Ghauri and Fang (2001) concluded in their study that "Chinese project managers are 'Confucian gentlemen' who look more for long-term working relationship to solve problems that may crop up at any time in than for a one-off legal deal” [8].

Guanxi plays an important role in dealing with external project stakeholders as well. Influenced by the traditional culture of collectivism, cooperativisim and most of all Confucianism, "Chinese project managers prefer to make the client happy, develop with the client personal relation/guanxi, and develop with contractor brother/sister relation/guanxi and long-term cooperation. Chinese project managers also need to develop good relationship/guanxi with clients and contractors for the purpose of conflict resolution” [9].

Based on the previous studies of project stakeholder management in China, we conducted an empirical study to examine the importance and uniqueness of guanxi management in Chinese projects.

\section{Research Settings and Methods Used}

In this study, we intend to focus on the informal relationship between project stakeholders and how it influence project success. This is a subjective and social phenomenon in the context of project stakeholder management. Thus, the research approach chosen for this study is an exploratory and qualitative study with data collected via questionnaire-based survey and key information interviews.

Questions designed in the questionnaire were all closed questions which were considered to be least biased, and given the fact that this study is a cross-cultural research, the questionnaire was translated into Chinese and re-translated to ensure the accuracy of the original translation. 20 project practitioners from Company A were chosen to be the respondents for questionnaire piloting. This was to ensure there were no ambiguous questions, confusion jargons, inaccurate expressions or low rate of responses [10]. After piloting, another 180 questionnaire copies were sent out via email to respondents in three companies, which were chosen according to the following criteria: they were project-based companies; they were familiar with modern project management knowledge, and they had rich experience in project management. A general description of the companies is seen in Table 1.

Table 1. Company information.

\begin{tabular}{ccc}
\hline & Company A & Company B \\
\hline Business & Chemical products for diverse industries & Financial consulting company \\
Number of employees & Approximately 1000 & Approximately 150 \\
Number of project managers & 16 during this study in conducted & 8 during this study is carried out $\quad 15$ during this study is conducted \\
\hline
\end{tabular}


The questionnaire response rate was $68 \%$ with 136 qualified copies returned. Because respondents were different in terms of their roles in projects, project experience and project sizes they normally work in, frequency distribution was then employed to analyzed respondents' characteristics. $28 \%$ of the respondents were project managers and the majority of them (72\%) were non-PM. The absolute majority (94\%) of the respondents had working experience of more than 5 years, while only 8 respondents reported project practice in less than 5 years. Finally, all respondents were required to report on the size of their largest project in their career. Most of the respondents were working on small and median size projects, and only 6 of them have participated in projects with budget of more than 50 million RMB.

Two researchers participated in the interviews and the analysis of data. The four interviews were all conducted in the form of face-to-face conversation with written words preserved and maintained for future reference and verification. The interviewees possessed several variables such as different working experience and different roles in projects so the subject was perceived from different perspectives. The four interviewees were a project managers, a project coordinator, a project consultant (from England) and a project team member. Even though researchers used sample questions in interviews, the interviewees were prompted to illustrate and expand on their initial responses, and sufficiently long time was given so that the interviewees can explore the subjects in depth, and no relevant information was missed out. In Section 4, we illustrate key observations with interview quotations, intending to give the reader a better opportunity to have a thorough understanding of interviewees' ideas towards the subject under discussion.

\section{General Findings}

In this section we present the results and the analysis from the empirical investigation. In Section 4.1, we discuss the relationship between project success and "guanxi", and Section 4.2 consists of three parts discussing "guanxi" within project team and with clients respectively.

\subsection{The Relationship between Project Success and "Guanxi"}

The classic cirterion of project success is a measure of the performance of a project against its main design parameters, which are schedule, budget, scope, and quality. However, it is agreed among various project management literature that "project success criteria should be project-specific and therefore determined by stakeholders at the start of each project [11]-[13]. Bearing in mind the various project success criteria, we examined every aspect in Chinese project delivery system, and discovered that one of the most important success criteria for Chinese project practitioners was establishing and maintaining good personal relationship (“guanxi”) among various stakeholders.

The first two statements in the questionnaire address the relationship between project success and stakeholder "guanxi". As shown from answers that $72 \%$ of the respondents expressed endorsement to the idea that stakeholder satisfaction is one of the most important project objectives, and they were willing to make much effort as possible to contribute to this objective. Only 9 people out of 136 strongly thought that personal relationship (“guanxi”) did not matter in achieving project success (see Figure 1).

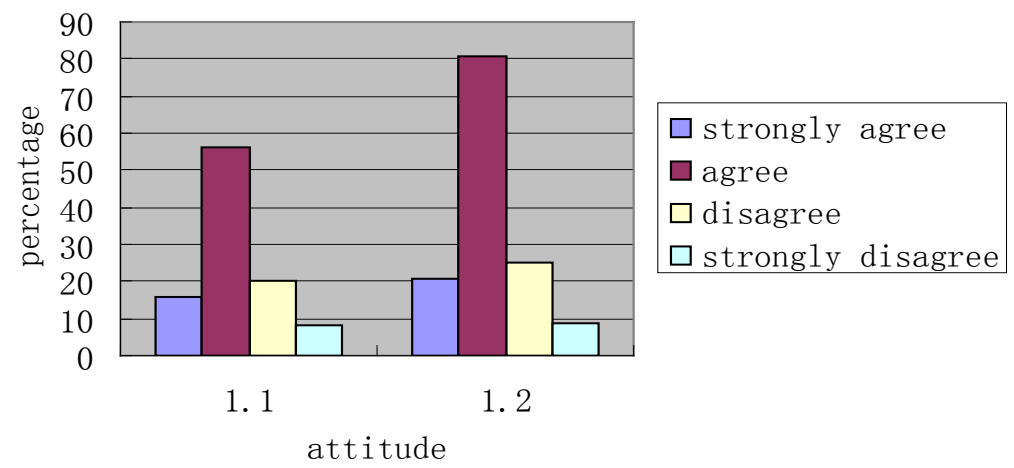

Figure 1. Project success and stakeholder relationship. Statement 1.1: Stakeholder satisfaction is one of the most important project objectives; Statement 1.2: A project is considered not an overall success if it affects key stakeholder relationship in the negative way. 
This finding was then supported by the follow-up interviews. “... even though some of our projects have successfully met the time-cost-quality requirements, they can still be considered as overall failures if project stakeholder "guanxi" was affected in the negative way. Especially for those key stakeholders, if a team member undermined relationship with a key stakeholder, he/she would be severely punished, or even be kicked out of the project team" (project manager). "Some of our project stakeholders including clients, contractors and even project team members themselves have personal relationship ("guanxi”) with each other, and maintaining that "guanxi" in good shape means further cooperation, high work efficiency and more business" (project coordinator).

It is worth mentioning that the results of the questionnaire showed a distinctive difference of opinion between project managers and non-PMs. All 39 project managers agreed that informal relationship had great influence on project success, and should be made important criteria in assessing a project's success. On the other hand, 40 non-PMs believed that as long as a project met time-cost-quality requirement, it was then a success even if stakeholder satisfaction was not achieved. Therefore, we assert that it was project managers who considered more about "guanxi” and considered it more important than non-PMs.

\subsection{Key Stakeholder "Guanxi"}

\subsubsection{Within Organization}

Questions concerning informal relationship within project teams were divided into three groups, each of which emphasizes one different aspect. The first group consists of question 2.1, 2.2 and 2.3 in questionnaire, and they examined how project practitioners conceive their relationship within their teams, and how they build up their personal/informal relationship (see Figure 2).

More than $80 \%$ of the respondents did consider their project team members more than just colleagues, $95 \%$ of them were willing to do personal favor if they were asked, and 86\% social with their team members quite often in order to build up and improve friendship with them. The results of the three questions also implied that most Chinese project practitioners preferred a friendly or even family-like work environment and they were willing to contribute to this objective. Martin was an English project consultant who had been working on a Chinese medical project for six months in Ningxia Province. In the interview with him, he said "the next day I arrived at Ningxia, my co-workers took me to visit the various tourist resorts, and they talked about everything but work. That was something I found very different from our way of doing things in England... What was interesting enough was when we finished a day's work, during dinners, they talked about nothing but work, and how emotionally they are involved in the work. They made toasts and did all kinds of things to show that everybody on that project was connected, personally connected, like a family".

As shown in Figure 3, Statement 2.4 revealed the internal bonding of project teams in another way by stating that new members always found it difficult to blend in a team at first, and he/she has to gradually show his/her allegiance to the team before he/she is finally considered a member of the "family". Statement 2.5 addressed another fact by showing that more than $70 \%$ of respondents would like to develop and maintain good informal

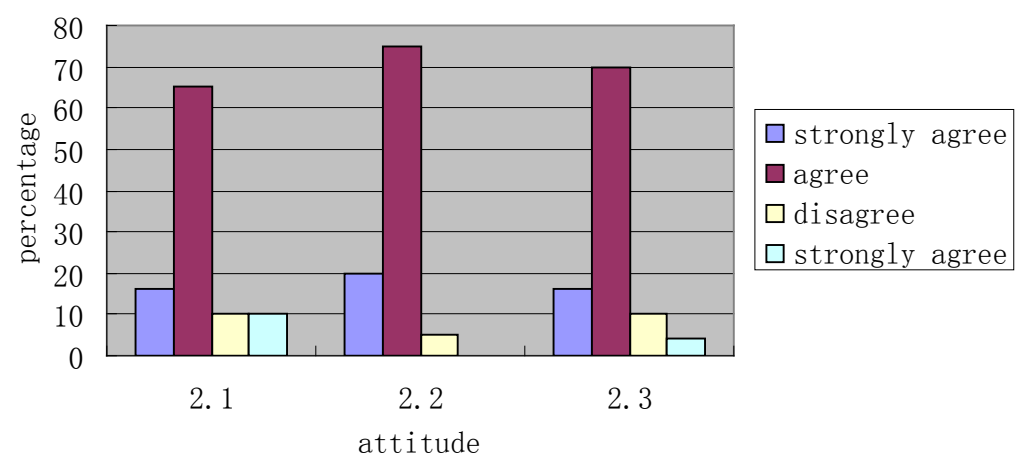

Figure 2. “Guanxi” within project team. Statement 2.1: I consider my project team members more friends or families rather than ONLY co-workers. Statement 2.2: I would do personal favors to co-workers when they ask for. Statement 2.3: I social with my co-workers after work, i.e. I have dinners with them, go shopping with them, etc. 


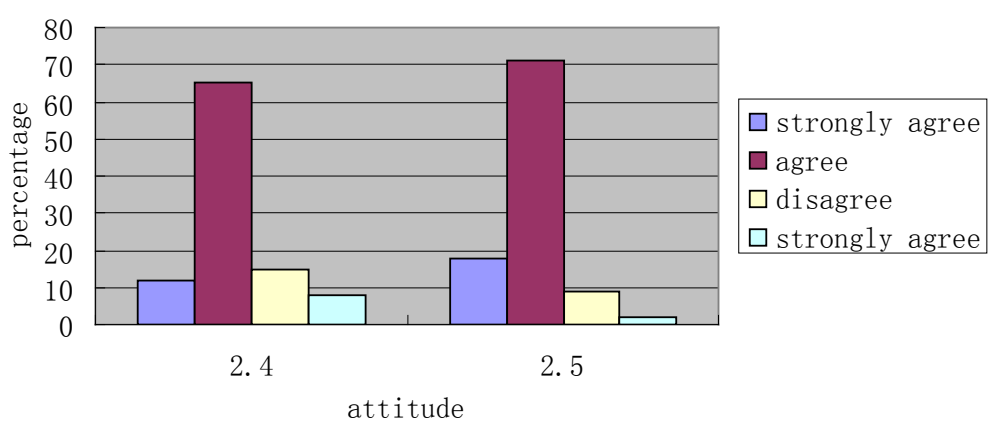

Figure 3. "Guanxi” within a project team and within an organization. Statement 2.4: New team members normally have difficulties blending in. Statement 2.5: If possible, I would like to develop and maintain good informal relationship with other project teams in the organization.

relationship with other project teams within the organization. "It is not unusual that there is conflict arising when two business units or two projects are competing for the same resources" [14]. When this kind of conflicts occur within an organization, higher levels of organizational hierarchies are normally the ones who make final decisions. However, in Chinese organizations, informal relationship between different project teams help mediating this conflicts through informal negotiations. "Especially when different projects are competing for personnel resources, they do sit down and negotiate. And if a person has the opportunity to choose to leave, go to or stay in a project team, their choices do show strong personal preference" (project team member). Yet Chinese project practitioners also realized that too close informal relationship can undermine work quality because "personal feelings are sometimes brought in work, and things can be really out of order" (project coordinator).

\subsubsection{With Clients}

Statements concerning guanxi with clients showed that $80 \%$ of the respondents preferred to develop personal relationship with their clients, because they believed that informal relationship with clients was essentially important for project success, despite the fact that developing and maintaining good informal relationship with clients can be time-consuming and sometimes leads to work delay. As shown in Figure 4, more than $70 \%$ of respondents strongly believed that good relationship with clients helps them win contracts, and more than $60 \%$ strongly agreed with the statement that clients have power in appointing or dismissing a project manager.

Statements 3.3, 3.4 and 3.5 further explored the relationship with clients. As shown in Figure 5, it was a very common practice for Chinese project managers to social with their clients outside work places. It was also noticed that one of the main purposes of building personal relationship with clients was to build up an efficient communication channel. When disagreement or conflicts occur, Chinese project managers seldom go through legal or contractual process to solve their disputes; instead, they chose informal negotiation with clients in order to reach an agreement. In doing so, not only dispute can be solved peacefully but also good client "guanxi" was able to be continued or even improved.

"We also spend a lot of time trying to build good relationship with potential clients, which helped us win some business" (project team member 1). This finding coincides with the conclusions from previous research that developing friendship is more effective in long-term partnership, and when guanxi is well established with project clients, many benefits will come along, such as mutual trust and efficient communication [15]. "Clients change their requirements sometimes, and good informal relationship helps to minimize the possibility of requirement change. When they do want to make changes, they would inform us before any formal process is taken so we will have time to prepare" (project coordinator).

It is also noticed that project clients also expect and make effort to establish good informal relationship with project teams, especially project managers. There are two major reasons for this. One is that clients expect to receive high quality from the project team with whom they have good guanxi with. And the other reason is that clients believe when a project team has a number of projects to choose, they often make their choices with consideration of their relationship with the potential clients. "We receive presents from our clients in holidays, especially during for spring holiday (Chinese lunar new year holiday). This happens quite often when the market is on our side" (project team member). 


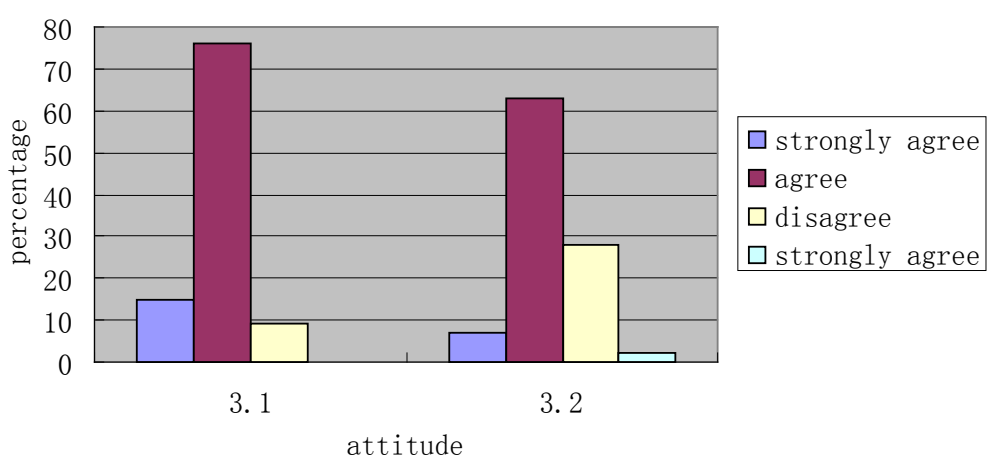

Figure 4. "Guanxi" with clients. Statement 3.1: Good guanxi with clients helps bringing in more business; Statement 3.2: Clients have power to appoint or dismiss a project manager.

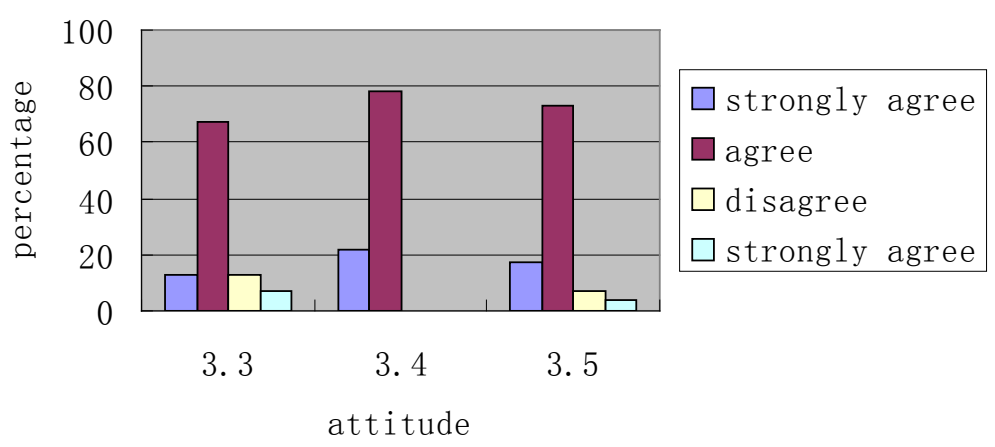

Figure 5. "Guanxi” with clients. Statement 3.3: Project managers social with their clients in order to establish or maintain good relationship. Statement 3.4: I prefer to solve disagreement with clients over dinner rather than referring to the conflict-settlement terms in contracts; Statement 3.5: Clients also expect good relationship with us, which they believe ensures high project quality.

\section{Conclusion and Future Research}

This paper contributes to the research field of project stakeholder management in China by shedding light on the informal relationship of project stakeholders. It was found that informal relationships among project stakeholders in Chinese projects play a deterministic role in project success, and are developed and maintained carefully by Chinese project practitioners.

However, this research only focused on relationships within project teams and with project clients. Guanxi exists in every dimension of a project and analysis of guanxi should include more stakeholders. For example, major external guanxi relationships include stakeholders such as boards of directors, shareholders, customers, media, legal groups and so on, while major internal guanxi relationships include company CEO, CFO, and various department managers within an organization. Future study should be conducted to investigate among as many stakeholders as possible.

\section{References}

[1] Lee, R.E. (2003) It Doesn’t Matter: “Mei Guanxi,” Cultural Difference, and Business Opportunities in the People’s Republic of China. In: Alon, I., Ed., Chinese Culture, Organizational Behaviour, and International Business Management, Greenwood Publishing Group, Inc., Santa Barbara, 165-168.

[2] Hutchings, K. and Michailova, S. (2004) Facilitating Knowledge Sharing in Russian and Chinese Subsidiaries: The Role of Personal Networks and Group Membership. Journal of Knowledge Management, 8, 84-94.

[3] Su, C., Ronald K.M. and Joseph M.S. (2007) Enabling Guanxi Management in China: A Hierarchical Stakeholder Model of Effective Guanxi. Journal of Business Ethics, 71, 301-319. http://dx.doi.org/10.1007/s10551-006-9140-3

[4] Batjargal, B. (2007) Comparative Social Capital: Networks of Entrepreneurs and Venture Capitalists in China and Russian. Management and Organization Review, 3, 397-419. http://dx.doi.org/10.1111/j.1740-8784.2007.00080.x 
[5] Morgan, R.M. and Hunt, S.D. (1994) The Commitment-Trust Theory of Relationship Marketing. Journal of Marketing, 22, 20-38. http://dx.doi.org/10.2307/1252308

[6] Pearce, J.A. and Robinson Jr., R.B. (2000) Cultivating Guanxi as a Foreign Investor Strategy. Business Horizons, 43, 31-39. http://dx.doi.org/10.1016/S0007-6813(00)87385-1

[7] Laaksonen, O. (1988) Management in China during and after Mao in Enterprises, Government, and Party. Walter De Gruyter Inc., Berlin, 378.

[8] Ghauri, P. and Fang, T. (2001) Negotiation with the Chinese: A Socio-Cultural Analysis. Journal of World Business, 36, 303-325. http://dx.doi.org/10.1016/S1090-9516(01)00057-8

[9] Wang, X.J. and Huang, J. (2006) The Relationships between Key Stakeholders' Project Performance and Project Success: Perceptions of Chinese Supervising Engineers. International Journal of Project Management, 24, 253-260. http://dx.doi.org/10.1016/j.ijproman.2005.11.006

[10] Ruane, J.M. (2005) Essentials of Research Methods: A Guide to Social Science Research. Blackwell Publishing, Hoboken.

[11] Judgev, K. and Muller, R. (2005) A Retrospective Look at Our Evolving Understanding of Project Success. Project Management Journal, 36, 19-31.

[12] Turner, J.R. (2004) Five Necessary Conditions for Project Success. International Journal of Project Management, 22, 349-350. http://dx.doi.org/10.1016/j.ijproman.2004.02.001

[13] Bannerman, P. (2008) Defining Project Success: A Multilevel Framework. Project Management Institute Research Conference, Warsaw, 5-6.

[14] Gutiérrez, E. and Magnusson, M. (2014) Dealing with Legitimacy: A Key Challenge for Project Portfolio Management Decision Makers. International Journal of Project Management, 32, 30.

[15] Yang, L., Shuai, C. and Ghazanfar, F. (2012) Factor Analysis of the Trust Structure between Owners and Contractors of Construction Projects Based on Structural Equation Modeling (SEM): A Case Study in China. African Journal of Business Management, 6, 2152-2161. 
Scientific Research Publishing (SCIRP) is one of the largest Open Access journal publishers. It is currently publishing more than 200 open access, online, peer-reviewed journals covering a wide range of academic disciplines. SCIRP serves the worldwide academic communities and contributes to the progress and application of science with its publication.

Other selected journals from SCIRP are listed as below. Submit your manuscript to us via either submit@scirp.org or Online Submission Portal.
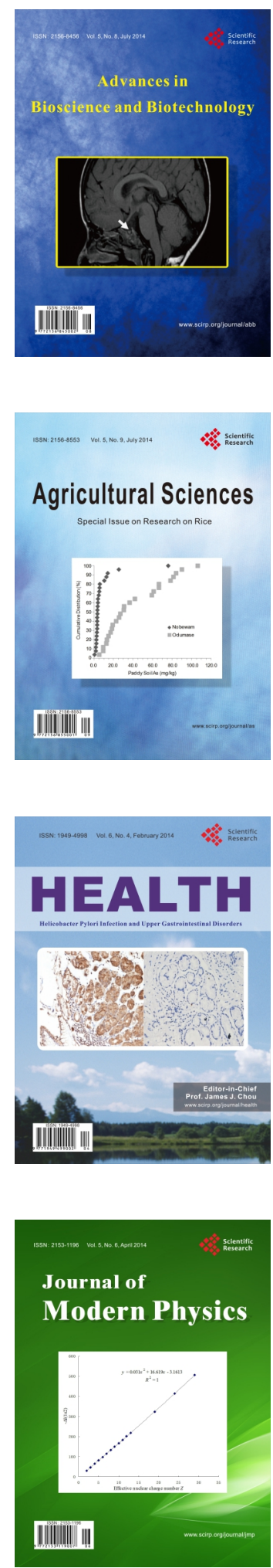
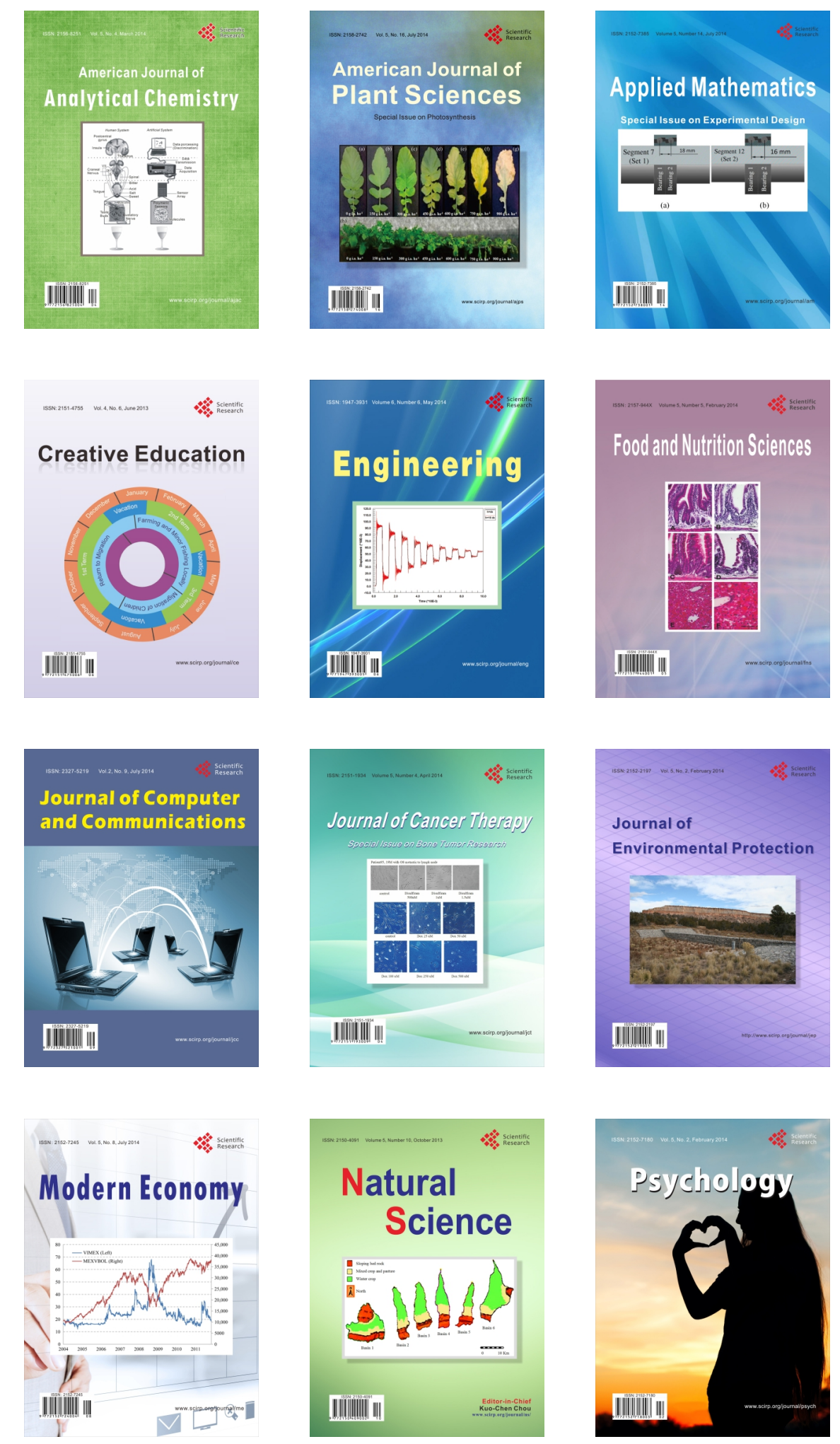